\title{
Research Paper: The Factors Associated With Olfactory Dysfunction in Patients with Multiple Sclerosis
}

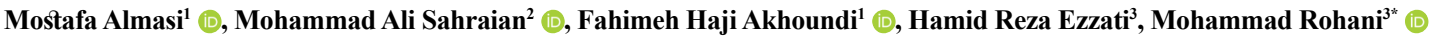

1. Department of Neurology, Firouzgar Hospital, Iran University of Medical Sciences, Tehran, Iran.

2. Multiple Sclerosis Research Center, Neuroscience Institute, Tehran University of Medical Sciences, Tehran, Iran.

3. Department of Neurology, Hazrat Rasool Hospital, Iran University of Medical Sciences, Tehran, Iran.

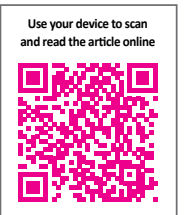

Cftation: Almasi, M., Sahraian, M. A., Haji Akhoundi, F., Ezzati, H. R., \& Rohani, M. (2021). The Factors Associated With Olfactory Dysfunction in Patients with Multiple Sclerosis. Basic and Clinical Neuroscience, 12(1), 89-94. http:/dx.doi. org $/ 10.32598 / \mathrm{bcn} \cdot 12 \cdot 1 \cdot 1368.1$

http://dx.doi.org/10.32598/ben.12.1.1368.1

Article info:

Received: 29 Apr 2018

First Revision: 20 May 2018

Accepted: 12 Feb 2020

Available Online: 01 Jan 2021

Keywords:

Smell, Olfaction disorders, Anosmia, Multiple Sclerosis, Secondary Progressive Multiple Sclerosis

\section{A B S T RA C T}

Introduction: An impaired sense of smell has a remarkable impact on the quality of life. It is seen in a variety of neurodegenerative diseases such as Parkinson disease. In this study, we assessed the olfactory function in patients with Multiple Sclerosis (MS) by Sniff Magnitude Test (SMT).

Methods: A cross-sectional study was conducted on 48 patients with MS. A questionnaire, including demographic and clinical variables, was completed for each patient. The SMT was used for the evaluation of olfactory function.

Results: Olfactory dysfunction was found in $14.6 \%$ of patients $(8.3 \%$ hyposmia and $6.3 \%$ anosmia). Older age, longer disease duration, higher hospital admission rate, lower minimental status examination score, and secondary progressive course of MS were significantly related to olfactory dysfunction.

Conclusion: Secondary progressive MS and markers of advanced disease toward neurodegenerative phase (including older age, longer disease duration, and lower cognitive function) can be associated with olfactory dysfunction in MS patients. 


\section{Highlights}

- Secondary progressive multiple sclerosis and markers of advanced disease toward the neurodegenerative phase can be associated with olfactory dysfunction in these patients.

\section{Plain Language Summary}

Two pathophysiologic mechanisms are involved in inflicting the damage in Multiple Sclerosis (MS): inflammation and neurodegeneration. Treatment modalities in MS mainly affect the inflammatory arm of the disease, and there is still nothing we can do about the neurodegenerative phase. The aim of the immunomodulatory and immunosuppressive therapies in MS is to delay the disease's progression toward the neurodegenerative phase. Early detection of the progression of the disease toward the neurodegenerative phase may help in providing a higher level of care for the patients. An impaired olfactory function has been established as an early finding in neurodegenerative diseases. In this study, we evaluated olfactory function in MS patients and we found that impaired olfaction was associated with signs of neurodegeneration. We proposed that olfactory evaluation can serve as an early detector of the progression of MS toward neurodegeneration.

\section{Introduction}

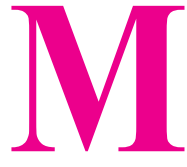

ultiple Sclerosis (MS) is an inflammatory disease characterized by myelin destruction in the Central Nervous System (CNS), leading to neuronal signaling impairment. Different systems in CNS, including optic nerves, corticospinal tracts, cerebellum, and its afferent and efferent pathways and brain stem, are involved in this disease (Compston \& Coles 2002; Rosati, 2001). With new treatment modalities, the quality of life in these patients has improved (Namjooyan et al., 2014).

Impaired sense of smell has a significant impact on the quality of life (Brämerson, Johansson, Ek, Nordin, \& Bende, 2004). Olfactory dysfunction is an essential finding in certain neurodegenerative diseases such as Parkinson disease, Alzheimer disease, Huntington disease, and motor neuron disease (Barresi et al., 2012). In recent years, studies proposed olfactory dysfunction in MS. These studies showed a relationship between olfactory dysfunction and psychiatric symptoms such as anxiety and depression, also with neurologic dysfunction and disability in MS patients (Barrios et al. 2007; Goektas et al., 2011).

Different-tests have been used for the analysis of olfaction in patients with MS, including University of Pennsylvania smell identification test, Sniffin's stick test, Connecticut chemosensory clinical research center test, and cross-cultural smell identification test (Doty \& Kamath 2014; Goektas et al., 2011; Silva et al. 2012; Sorokowska et al., 2015; Zorzon et al., 2000). These tests are based on odor identification and olfaction's threshold (Eibenstein et al., 2005). The Sniff
Magnitude Test (SMT) is a new method for analyzing olfaction and evaluating the decremented sensation of unpleasant odors. SMT does not need verbal communication with the patient, which is one of the advantages of this test. So it can be used easily in every patient, including demented ones. This test is not affected by memory function, attention, and the patient's culture (Dulay et al., 2008; Frank et al., 2006; Frank, Dulay, \& Gesteland, 2003; Tourbier \& Doty, 2007).

In the present study, we used the SMT to assess olfactory function in patients with MS. We also evaluated the relationship between disease duration, its progression to the secondary progressive stage, and impaired cognition with olfactory function in MS patients.

\section{Materials and Methods}

This cross-sectional study was conducted on the patients with MS referred to neurology clinics of RasoolAkram and Sina hospitals (two university-affiliated hospitals). All consequent MS patients entered the study after giving informed consent. The exclusion criteria were disease duration of less than one year and any attacks in the past 6 months. Demographic and clinical data were gathered using a questionnaire. The following data were registered for all patients: age, sex, education level, history of smoking, self-report history of hypertension, hyperlipidemia, diabetes mellitus, and other medical diseases, family history of MS, duration of the disease, the course of the disease (i.e. Relapsing-Remitting [RR], Primary Progressive [PP] or Secondary Progressive [SP]), and the number of hospital admissions for receiving I.V steroids. The cognitive function of the pa- 
tients was also recorded using the Mini-Mental State Examination (MMSE) score. A computerized device performed the sniff magnitude test with four canisters, each containing $5 \mathrm{~mL}$ light mineral 3\% saturated oil. Canister number 1 was the "null" canister and non-odorized. The other canisters contained 3\% methylthiobutyrate, 3\% ethyl 3-mercaptopropionate, and 3\% isomil acetate. According to SMT, the olfactory function of the patients was categorized as normal, hyposmia, and anosmia. Finally, the data were collected, coded, and analyzed in SPSS version 16.0. Descriptive statistics are given as the Mean \pm SD or frequency (percentage). The Student's ttest was used to compare between-groups means and the Fisher exact-test to compare nominal variables.

\section{Result}

A total of 48 patients with MS were studied, including $14(29.2 \%)$ males and $34(70.8 \%)$ females. Their Mean \pm SD age was $36.9 \pm 10.1$ years (ranging from 14 to 57 years). Four patients $(8.3 \%)$ had a family history of MS, and 12 patients $(27.1 \%)$ had a smoking history.

Regarding the disease course, 33 patients $(68.8 \%)$ were RRMS, 6 (12.5\%) PPMS and 9 (18.8\%) SPMS. The Mean \pm SD duration of the disease was $8.4 \pm 5.7$ years (ranging from 1 to 25 years), and the mean admission times in hospital was 5.1 (3.1) (range of 1 to 14). Their Mean \pm SD MMSE score was $27.7 \pm 1.5$ (with a minimum of 24 and a maximum of 30 ). The frequency of olfactory dysfunction in the patients was $14.6 \%$, including 4 patients $(8.3 \%)$ with hyposmia and 3 patients $(6.3 \%)$ with anosmia.

Table 1. Comparison of demographic and clinical variables in patients with and without olfactory dysfunction

\begin{tabular}{|c|c|c|c|}
\hline \multirow[b]{2}{*}{ Demographic and Clinical Variables } & \multicolumn{2}{|c|}{ No. (\%) } & \multirow[b]{2}{*}{$\mathbf{P}$} \\
\hline & $\begin{array}{l}\text { Patients With Olfactory } \\
\text { Dysfunction } \\
(n=7)\end{array}$ & $\begin{array}{l}\text { Patients Without Olfactory } \\
\text { Dysfunction } \\
(n=41)\end{array}$ & \\
\hline \multirow[b]{3}{*}{ Female } & $3(42.8)$ & $11(26.8)$ & \multirow{3}{*}{0.32} \\
\hline & & & \\
\hline & $4(57.1)$ & $30(73.1)$ & \\
\hline Age (y) Mean $\pm S D$ & $48.5 \pm 7.8$ & $34.9 \pm 9.1$ & 0.001 \\
\hline Under High school diploma & $1(14.3)$ & $7(17.1)$ & \multirow{5}{*}{0.07} \\
\hline High school diploma & $3(42.9)$ & $24(58.5)$ & \\
\hline Education level & & & \\
\hline Bachelor's degree & $1(14.3)$ & $9(22)$ & \\
\hline Master's degree and Doctorate & $2(28.6)$ & $1(2.4)$ & \\
\hline Smoking & $2(28.6)$ & $11(26.8)$ & 0.62 \\
\hline Family history of MS & $1(14.3)$ & $3(7.3)$ & 0.48 \\
\hline Hypertension & 0 & $1(2.1)$ & 0.14 \\
\hline Diabetes mellitus & $1(2.1)$ & 0 & 0.14 \\
\hline Hyperlipidemia & $2(28.6)$ & $3(7.3)$ & 0.85 \\
\hline \multirow[t]{3}{*}{ Relapsing remitting MS } & $2(28.6)$ & $31(75.6)$ & \multirow{3}{*}{0.01} \\
\hline & $1(14.3)$ & $5(12.2)$ & \\
\hline & $4(57.1)$ & $5(12.2)$ & \\
\hline Disease duration (years) Mean $\pm S D$ & $12.8 \pm 8.0$ & $7.6 \pm 3.0$ & 0.02 \\
\hline Number of hospital admissions, Mean \pm SD & $8.2 \pm 4.1$ & $4.5 \pm 2.6$ & 0.003 \\
\hline MMSE score, Mean \pm SD & $25.2 \pm 0.9$ & $28.1 \pm 1.1$ & 0.0001 \\
\hline
\end{tabular}


Regarding the demographic variables, the age was correlated with olfactory dysfunction, i.e. patients with olfactory dysfunction were older than those with normal olfaction (48.5 \pm 7.8 years vs. $34.9 \pm 9.1$ years respectively, $\mathrm{P}=0.001$ ). The sex, level of education, history of smoking, family history of MS, hypertension, hyperlipidemia, and diabetes mellitus were not related to olfactory dysfunction (Table 1).

Considering disease course, olfactory dysfunction was more prevalent in SPMS than RRMS and PPMS $(\mathrm{P}=0.01)$. Disease duration and hospital admission rates were higher in patients with olfactory dysfunction. The Mean \pm SD MMSE score in patients with olfactory dysfunction was $25.2 \pm 0.9$ and in patients without olfactory dysfunction was $28.1 \pm 1.1$, which was significantly different $(\mathrm{P}<0.001)$.

\section{Discussion}

MS is a disease of CNS with axonal demyelination and degeneration. Disturbance of olfaction happens in neurodegenerative diseases such as Parkinson disease, Alzheimer disease, Huntington disease, and motor neuron disease (Bacon Moore, Paulsen, \& Murphy, 1999; Barresi et al. 2012; Kovács 2004; Tissingh et al., 2001). Surprisingly in Parkinson disease, development of olfactory dysfunction even precedes motor symptoms (Hawkes, Shephard \& Daniel, 1999). Some studies showed an olfactory disturbance in MS is more prevalent than the normal population (Doty \& Kamath, 2014; Silva et al., 2012; Zorzon et al. 2000). The frequency of olfactory dysfunction in MS patients was estimated between $11 \%$ and $44 \%$ in previous studies (Doty, Li, Mannon, \& Yousem, 1999; Silva et al., 2012; Zivadinov et al., 1999; Zorzon et al., 2000), and our study revealed a prevalence of $14.6 \%$. These variable results can be explained by choosing different-tests of olfactory assessment. We used SMT with test-retest reliability of 0.8 according to the study of Frank et al. (2003). The advantage of SMT is its independence of language and cognitive ability of patients (Dulay et al., 2008; Frank et al., 2006).

Based on our results, MS patients with olfactory dysfunction were older. Aging by itself is one cause of olfactory dysfunction. On the other hand, higher age in MS means more prolonged disease duration and progression in the disease course. Also, olfactory dysfunction was directly related to the disease's duration and the number of disease attacks (or admission times to hospital). In the study of Zivadinov, Zorzon, Bragadin, Pagliaro, \& Cazzato (1999) the severity of neurologic dysfunction was inversely related to smell identification score
(Goektas et al. 2011). In another study, the score of the Expanded Disability Status Scale (EDSS) in MS patients was higher in patients with impaired discrimination and identification of smells (Dahlslett et al., 2012). In the brain imaging of MS patients, there was a correlation between olfactory dysfunction and the number of white matter lesions in temporal and inferior frontal lobes (DeLuca et al., 2015; Doty \& Kamath, 2014; Zorzon et al., 2000) and decreased volumetric measurements of olfactory bulbs (Goektas et al. 2011).

This study showed a higher prevalence of olfactory dysfunction in SPMS patients compared to RRMS and PPMS. Silva and colleagues achieved similar results and suggested that olfactory situation can be used as a clinical marker of SPMS (Silva et al., 2012).

Some studies debated that anxiety, depression, and cognitive dysfunction in MS patients could be relevant to olfactory dysfunction (Kostić, Stefanova, Pekmezović, \& Drulović, 2009; Zivadinov et al., 1999). We assess the MMSE score as the marker of cognition in this study and figured out lower MMSE scores in patients with olfactory dysfunction. Schubert et al. showed a significant association between olfactory impairment at baseline and a 5 -year incidence of cognitive impairment (the odds ratio was 6.62) (Schubert et al., 2008). In Korean older adults, low cognitive performance was associated with loss of olfactory sensitivity (Seo, Jeon, Hummel, \& Min,, 2009).

Based on our result, the olfactory impairment in patients with MS is related to more severe disease and lower MMSE scores. Regarding this point, lower MMSE scores in patients with MS are related to more severe illness and plaque burden (Karadayi et al., 2014; Rogers \& Panegyres, 2007; Sastre-Garriga et al., 2009), the olfactory dysfunction may use as a marker to show the severity of disease and neurologic disability. For this reason and the significant effect of smelling on the quality of life, screening of olfaction can be considered as a helpful assessment in MS patients.

We didn't include EDSS scores and brain MRI of our patients in this study due to the lack of this information in all of our patients, which are the most important limitations and negative points of our research. However, we highly emphasize considering these factors in future studies with larger sample sizes.

\section{Conclusion}

In conclusion, olfactory dysfunction in patients with MS is associated with advanced disease stage (SPMS, longer disease duration, and higher hospital admission 
rates) and lower cognitive function. Thus olfactory dysfunction could serve as a potentially useful marker of the advanced stages of the disease. Considering the results of our study and also the major effects of olfaction on the quality of life, assessment of olfaction in MS patients is recommended.

\section{Ethical Considerations}

Compliance with ethical guidelines

This study was approved by the ethics committee of Iran University of Medical Sciences. The subjects signed informed consents to participate in this study.

Funding

This research did not receive any grant from funding agencies in the public, commercial, or non-profit sectors.

\section{Authors' contributions}

Data collection: Hamidreza Ezzati; Original draft preparation and data analysis: Mostafa Almasi; Review \& editing: Mohammad Ali Sahraian; Review \& editing and data analysis: Fahimeh H. Akhoundi; Conceptualization; Review \& editing: Mohammad Rohani.

\section{Conflict of interest}

The authors report no conflict of interest.

\section{References}

Bacon Moore, A., Paulsen, J. S., \& Murphy, C. (1999). A test of odor fluency in patients with Alzheimer's and Huntington's disease. Journal of Clinical and Experimental Neuropsychology, 21(3), 341-51. [DOI:10.1076/jcen.21.3.341.918] [PMID]

Barresi, M., Ciurleo, R., Giacoppo, S., Cuzzola, V. F., Celi, D., \& Bramanti, P., et al. (2012). Evaluation of olfactory dysfunction in neurodegenerative diseases. Journal of the Neurological Sciences, 323(1-2), 16-24. [DOI:10.1016/j.jns.2012.08.028] [PMID]

Barrios, F. A., Gonzalez, L., Favila, R., Alonso, M. E., Salgado, P. M., \& Diaz, R., et al. (2007). Olfaction and neurodegeneration in HD. Neuroreport, 18(1), 73-6. [DOI:10.1097/ WNR.0b013e3280102302] [PMID]

Brämerson, A., Johansson, L., Ek, L., Nordin, S., \& Bende, M. (2004). Prevalence of olfactory dysfunction: The Skövde population-based study. The Laryngoscope, 114(4), 733-7. [DOI:10.1097/00005537-200404000-00026] [PMID]

Compston, A., \& Coles, A. 2002. Multiple Sclerosis. The Lancet, 359(9313), 1221-31. [DOI:10.1016/S0140-6736(02)08220-X]
Dahlslett, S. B., Goektas, O., Schmidt, F., Harms, L., Olze, H. \& Fleiner, F. (2012). Psychophysiological and electrophysiological testing of olfactory and gustatory function in patients with multiple sclerosis. European Archives of Oto-Rhino-Laryngology 269(4), 1163-9. https://link.springer.com/article/10.1007/ s00405-011-1812-7

DeLuca, G. C., Joseph, A., George, J., Yates, R. L., Hamard, M., \& Hofer, M., et al. (2015). Olfactory pathology in central nervous system demyelinating diseases. Brain Pathology, 25(5), 543-51. [DOI:10.1111/bpa.12209] [PMID]

Doty, R. L., Li, C., Mannon, L. J., \& Yousem, D. M. (1999). Olfactory dysfunction in multiple sclerosis: Relation to longitudinal changes in plaque numbers in central olfactory structures. Neurology, 53(4), 880. [DOI:10.1212/WNL.53.4.880] [PMID]

Doty, R. L., \& Kamath, V. (2014). The influences of age on olfaction: A review. Frontiers in Psychology, 5, 20. [DOI:10.3389/ fpsyg.2014.00020] [PMID] [PMCID]

Dulay, M. F., Gesteland, R. C., Shear, P. K., Ritchey, P. N., \& Frank, R. A. (2008). Assessment of the influence of cognition and cognitive processing speed on three tests of olfaction Journal of Clinical and Experimental Neuropsychology, 30(3), 32737. [DOI:10.1080/13803390701415892] [PMID]

Eibenstein, A., Fioretti, A. B., Lena, C., Rosati, N., Amabile, G., \& Fusetti, M. (2005). Modern psychophysical tests to assess olfactory function. Neurological Sciences, 26(3), 147-55. [DOI:10.1007/s10072-005-0452-3] [PMID]

Frank, R. A., Gesteland, R. C., Bailie, J., Rybalsky, K., Seiden, A., \& Dulay, M. F. (2006). Characterization of the sniff magnitude test. Archives of Otolaryngology-Head \& Neck Surgery, 132(5), 532-6. [DOI:10.1001/archotol.132.5.532] [PMID]

Frank, R. A., Gesteland, R. C., Bailie, J., Rybalsky, K., Seiden, A., \& Dulay, M. F. (2006). Characterization of the sniff magnitude test. Archives of Otolaryngology-Head \& Neck Surgery, 132(5) 532-6. https://jamanetwork.com/journals/jamaotolaryngology/article-abstract/ 484156

Frank, R. A., Dulay, M. F., \& Gesteland, R. C. (2003). Assessment of the Sniff Magnitude Test as a clinical test of olfactory function. Physiology \& Behavior, 78(2), 195-204. [DOI:10.1016/ S0031-9384(02)00965-4]

Goektas, O., Schmidt, F., Bohner, G., Erb, K., Ludemann, L., \& Dahlslett, B., et al. (2011). Olfactory bulb volume and olfactory function in patients with multiple sclerosis. Rhinology, 49(2), 221-6. [DOI:10.4193/rhino10.136] [PMID]

Hawkes, C. H., Shephard, B. C., \& Daniel, S. E. (1999). Is Parkinson's disease a primary olfactory disorder?. QJM: An International Journal of Medicine, 92(8), 473-80. https:/ / academic.oup. com/qjmed/article/92/8/473/1563212?login=true

Karadayi, H., Arisoy, O., Altunrende, B., Boztas, M. H., \& Sercan, M. (2014). The relationship of cognitive impairment with neurological and psychiatric variables in multiple sclerosis patients. International Journal of Psychiatry in Clinical Practice, 18(1), 45-51.[DOI:10.3109/13651501.2013.845221] [PMID]

Kostić, J., Stefanova, E., Pekmezović, T., \& Drulović, J. (2009). Correlation between olfactory dysfunction and various clinical parameters in patients with Multiple Sclerosis. Vojnosanitetski Pregled, 66(3), 203-6. [DOI:10.2298/VSP0903203K] [PMID] 
Kovács, T. (2004). Mechanisms of olfactory dysfunction in aging and neurodegenerative disorders. Ageing Research Reviews, 3(2), 215-32. [DOI:10.1016/j.arr.2003.10.003] [PMID]

Namjooyan, F., Ghanavati, R., Majdinasab, N., Jokari, S., \& Janbozorgi, M. (2014). Uses of complementary and alternative medicine in multiple sclerosis. Journal of Traditional and Complementary Medicine, 4(3), 145-52. [DOI:10.4103/22254110.136543] [PMID] [PMCID]

Rogers, J. M., \& Panegyres, P. K. (2007). Cognitive impairment in multiple sclerosis: Evidence-based analysis and recommendations. Journal of Clinical Neuroscience, 14(10), 919-27. https://www.sciencedirect.com/science/article/abs/pii/ S0967586807001245

Rosati, G. (2001). The prevalence of multiple sclerosis in the world: An update. Neurological Sciences, 22(2), 117-39. [DOI:10.1007/s100720170011] [PMID]

Sastre-Garriga, J., Arévalo, M. J., Renom, M., Alonso, J., González, I., \& Galán, I., et al. (2009). Brain volumetry counterparts of cognitive impairment in patients with multiple sclerosis. Journal of the Neurological Sciences, 282(1-2), 120-4. [DOI:10.1016/j.jns.2008.12.019] [PMID]

Schubert, C. R., Carmichael, L. L., Murphy, C., Klein, B. E., Klein, R., \& Cruickshanks, K. J. (2008). Olfaction and the 5-year incidence of cognitive impairment in an epidemiological study of older adults. Journal of the American Geriatrics Society, 56(8), 1517-21. [DOI:10.1111/j.1532-5415.2008.01826.x]

Seo, H. S., Jeon, K. J., Hummel, T., \& Min, B. C. (2009). Influences of olfactory impairment on depression, cognitive performance, and quality of life in Korean elderly. European Archives of Oto-Rhino-Laryngology, 266(11), 1739-45. https:/ /link. springer.com/article/10.1007/s00405-009-1001-0

Silva, A. M., Santos, E., Moreira, I., Bettencourt, A., Coutinho, E., \& Gonçalves, A., et al. (2012). Olfactory dysfunction in multiple sclerosis: Association with secondary progression. Multiple Sclerosis Journal, 18(5), 616-21. [DOI:10.1177/1352458511427156] [PMID]

Sorokowska, A., Schriever, V. A., Gudziol, V., Hummel, C., Hähner, A., \& Iannilli, E., et al. (2015). Changes of olfactory abilities in relation to age: Odor identification in more than 1400 people aged 4 to 80 years. European archives of Oto-rhinolaryngology, 272(8), 1937-44. [DOI:10.1007/s00405-014-3263-4] [PMID] [PMCID]

Tissingh, G., Berendse, H. W., Bergmans, P., DeWaard, R., Drukarch, B., \& Stoof, J. C., et al. (2001). Loss of olfaction in de novo and treated Parkinson's disease: possible implications for early diagnosis. Movement Disorders: Official Journal of The Movement Disorder Society, 16(1), 41-6. [DOI.org/10.1002/15318257(200101)16:1<41::AID-MDS1017>3.0.CO;2-M]

Tourbier, I. A., \& Doty, R. L. (2007). Sniff magnitude test: relationship to odor identification, detection, and memory tests in a clinic population. Chemical Senses, 32(6), 515-23. [Doi. org/10.1093/chemse/bjm020]

Zivadinov, R., Zorzon, M., Bragadin, L. M., Pagliaro, G., \& Cazzato, G. (1999). Olfactory loss in multiple sclerosis. Journal of the Neurological Sciences, 168(2), 127-30. [DOI:10.1016/S0022$510 \times(99) 00189-6]$

Zorzon, M., Ukmar, M., Bragadin, L. M., Zanier, F., Antonello, R. M., \& Cazzato, G., et al. (2000). Olfactory dysfunction and extent of white matter abnormalities in multiple sclerosis: a clinical and MR study. Multiple Sclerosis Journal, 6(6), 386-90. [DOI:10.1191/135245800701566368] [PMID] 